\title{
Day-to-day Variability in the Normal Electrocardiogram
}

\author{
LEON MICHAELS AND REMI J. CADORET
}

\author{
From the Department of Medicine, University of Manitoba, Winnipeg, Canada
}

The characteristics of the normal adult electrocardiogram have been established by analysis of records obtained from large numbers of clinically healthy subjects (Kossmann and Johnston, 1935; Myers et al., 1947; Sokolow and Friedlander, 1949; Hiss, Lamb, and Allen, 1960). The limits of normal as established by these authors are very wide, the duration and amplitude of the waves and the lengths of the intervals between them varying considerably.

The extent to which serial electrocardiograms recorded in any one person remain constant or vary within the wide range of the population normal is as yet unknown. The need for defining the extent of this "intra-individual" variability is great, as dayto-day changes are frequently seen in serial electrocardiograms of patients suspected of having heart disease. It has not hitherto been possible to assess the significance of such changes if each one of the tracings has been within the limits of normal, though clearly differing from the others. The present study was, therefore, undertaken to determine the extent to which the normal electrocardiogram varies from day to day in any one person.

\section{SUBJECTS AND METHODS}

The electrocardiograms used in the present study were recorded in 36 men and 22 women aged from 30 to 70 years. Three were Medical Centre employees and clinically healthy. The remainder were ambulant patients in the Winnipeg General Hospital or the Central Tuberculosis Clinic of Manitoba who were suffering from conditions considered unlikely to affect the cardiovascular system. Ten had localized pulmonary tuberculosis, 18 had orthopædic conditions, 18 had "localized" surgical diseases such as a hernia, and 5 had other ill-

Received March 28, 1967. nesses. None had associated conditions that might have affected the electrocardiogram reflexly. A few patients had mild cough or very slight breathlessness on effort. No patient was otherwise dyspnœic and none had chest pain that was other than momentary. In no patient was any abnormality detected on physical examination of the cardiovascular system. The highest systolic blood pressure recorded was 155 and the highest diastolic $90 \mathrm{~mm}$. $\mathrm{Hg}$. The heart was radiologically normal in all. The electrocardiograms were individually normal according to the standards of the Criteria Committee of the New York Heart Association (1964).

Twelve lead electrocardiograms were recorded in all subjects between 9.00 and 10.00 a.m. on each of four consecutive days. During this period they were not subjected to any procedures likely to alter cardiovascular function, e.g. anæsthesia or operation. No food, drink, or tobacco were allowed after the midnight of the four consecutive preceding nights, and all therapy was similarly withheld until after the tracings had been obtained. No patient was in pain during the recordings and all seemed relaxed. The same couch and pillow were used throughout and five minutes' rest were allowed before starting the recordings. The same Sanborn Twin-beam Model 62 and accessories were used throughout. The calibration was standardized at $1 \mathrm{~cm}$. deflection per millivolt and the standardizing recorded with each lead. Paper speed was $25 \mathrm{~mm}$. per second. The six positions of the chest lead electrodes were marked with a skin pencil to ensure identical placement on all four occasions.

The various parameters were measured in the manner described by Goldberger (1949), using a hand lens for increased accuracy. $P-R$ intervals were measured in lead II, and QRS in leads II and V1-6, in all cases to the nearest hundredth of a second. The maximum inter-day variations were recorded for each subject and the population means and standard deviations calculated. Amplitude measurements were usually obtained by averaging six complexes, but, where there was obvious respiratory variation, the complexes recorded through one respiratory cycle were averaged. All results were checked by a second observer. The amplitude data were punched on cards and calculations made 
with a 1620 I.B.M. computer. Waves that were inconstant or less than $0 \cdot 1$ tenths of a millivolt were excluded from the computations as were amplitudes that were not readily measurable, such as $S-T$ segments that sloped upwards. No calculations were made in the cases of waves that appeared in less than five subjects.

The total variances of the amplitude differences between the first and the second days were calculated for the $P, Q, R, S$, and $T$ waves and for the $S-T$ segments, using the following formula.

Total variance $=\sum_{1=1} \sum_{j=1}^{2}\left(\mathrm{x}_{1 \mathrm{j}}-\overline{\mathrm{x}}_{1 \cdot}-\overline{\mathrm{x}}_{. j}+\overline{\overline{\mathrm{x}}} . .\right)^{2}$ when $j=$ days 1,2 .; $i=$ subjects $1,2 \ldots s . ; x_{1 j}=$ amplitude for person $i$ on day $j ; \bar{x}_{1} .=$ mean for person $i$ for all days; $\overline{\mathbf{x}}_{\cdot j}=$ mean for all persons for day $j ; \overline{\overline{\mathbf{x}}} . .=$ grand mean.

The total variances for the third and fourth days were similarly calculated and the total variances for the first two plus the last two days obtained by addition. Mean variances were derived by dividing total variences by the number of degrees of freedom $(d-1)(s-1)^{\star}$. Subsequent references to variances (mean or total) refer to the variances of day-to-day amplitude differences as thus computed. References to standard deviations (SD) refer to the square roots of the mean variances as thus defined.

The upper limits of normal for the day-to-day variations in amplitude of each wave were based on 95 per cent confidence limits and have been termed the "maximal permissible day-to-day differences". They were calculated by multiplying the standard deviation by 1.645 rather than $2 \cdot 0$, as we were concerned solely with determining the upper limits of normal. The mean variance as defined corresponds to the "random" variance V of Simonson, Brozek, and Keys (1949), and the method of calculating the maximal permissible day-today difference corresponds to the one employed by these authors.

In the case of the $P$ and $Q$ waves and the $S-T$ segments, calculations were confined to determinations of mean variance, using the pooled data for all days and both sexes. More detailed analysis was not considered practical as the mean variances were exceedingly small (see Tables III and V). In the case of the R, S, and T waves the mean variances of the first and last two pairs of days were compared and the coefficients of correlation of mean variance with age and with mean wave amplitude computed, the $t$ test being used to determine significance. Initially the sexes were treated separately; subsequently these correlations were calculated for the whole population.

\section{RESULTS}

Qualitative Observations. In 3 patients the rhythm varied between complete regularity and slight sinus arrhythmia. It was unchanged in all others. Occasional atrial or ventricular ectopic beats were an inconstant feature in 7 patients.

$\star d=$ no. of days; $s=$ no. of subjects.
Each subject's electrocardiogram tended to have certain distinctive features by which it could be recognized. These included the detailed configuration of the various waves, the contours of the S-T segment, and the extent of respiratory variation. These features, while not lending themselves to measurement, were noted to be remarkably constant. In no case, for example, did a rounded $P$ wave become pointed, or a straight S-T segment curved. Other distinctive features were minor slurring or notching of the QRS complexes or the presence of a $U$ wave. These were noted in the tracings of 48 subjects. In 43 they showed minimal variation or were completely constant. In 5, notching of very minor degree appeared in a second or later tracing or, having been present initially, disappeared.

Quantitative Observations. The greatest variations in heart rate from first to fourth day averaged $7 \pm 5 \cdot 1$ beats per minute. There was no consistent tendency for the rate to be fastest or slowest on any one day. The mean day-to-day change in frontal plane QRS axis was $6^{\circ} \pm 2 \cdot 8^{\circ}$. Variations in P-R and QRS intervals and the maximal permissible day-to-day differences are shown in Table I.

TABLE I

DIFFERENCES IN SECONDS BETWEEN SHORTEST AND LONGEST P-R AND ORS INTERVALS OBSERVED IN FOUR CONSECUTIVE ELECTROCARDIOGRAMS

\begin{tabular}{|c|c|c|c|c|}
\hline Interval & P-R & \multicolumn{3}{|c|}{ QRS } \\
\hline Lead & II & II & V1-3 & V4-6 \\
\hline $\begin{array}{l}\text { Mean difference } \\
\text { Standard deviation } \\
\text { Maximal permissible day- } \\
\text { to-day difference }\end{array}$ & $\begin{array}{l}0.01 \\
0.010 \\
0.03\end{array}$ & $\begin{array}{l}0.01 \\
0.006 \\
0.02\end{array}$ & $\begin{array}{l}0.01 \\
0.004 \\
0.02\end{array}$ & $\begin{array}{l}0.01 \\
0.009 \\
0.03\end{array}$ \\
\hline
\end{tabular}

Comparison of the $R, S$, and $T$ wave standard deviations of the first and the last two pairs of days showed insignificant differences ${ }^{\star}$. Further analyses were therefore based on the combined data of days 1 and 2 , and days 3 and 4 . There were altogether 36 comparisons of men and women (Table II), the $\mathrm{R}, \mathrm{S}$, and $\mathrm{T}$ wave standard deviations being studied in all 12 leads. The standard deviations were larger in men on 21 occasions, notably in the chest leads, but the absolute differences were very small, exceeding 0.5 tenths of a millivolt on only 4 of the 36 occasions and reaching one-tenth of a millivolt only once. Pooling the data obtained in each sex was

* Details of this comparison and additional data not included in the Tables are available in cyclostyled form on request. 
TABLE II

COMPARISON OF STANDARD DEVIATIONS (IN TENTHS OF A MILLIVOLT) IN MEN AND WOMEN

\begin{tabular}{|c|c|c|c|c|c|c|}
\hline \multirow[t]{3}{*}{ Lead } & \multirow{2}{*}{\multicolumn{2}{|c|}{ 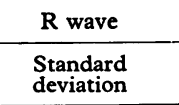 }} & \multirow{2}{*}{\multicolumn{2}{|c|}{$\begin{array}{c}\text { S wave } \\
\begin{array}{l}\text { Standard } \\
\text { deviation }\end{array}\end{array}$}} & \multirow{2}{*}{\multicolumn{2}{|c|}{$\begin{array}{c}\mathrm{T} \text { wave } \\
\begin{array}{l}\text { Standard } \\
\text { deviation }\end{array} \\
\end{array}$}} \\
\hline & & & & & & \\
\hline & Men & Women & Men & Women & Men & Women \\
\hline $\begin{array}{l}\text { I } \\
\text { II } \\
\text { III } \\
\text { aVR } \\
\text { aVL } \\
\text { aVF } \\
\text { V1 } \\
\text { V2 } \\
\text { V3 } \\
\text { V4 } \\
\text { V5 } \\
\text { V6 }\end{array}$ & $\begin{array}{l}0.6^{\star} \\
0.6 \\
0.5 \\
0.1 \\
0.4 \\
0.5 \\
0.3 \\
0.6 \\
1.5 \\
\mathbf{2 . 2} \\
1.3 \\
0.8 t\end{array}$ & $\begin{array}{l}0.4 \\
0.3 \\
0.4 \\
0 \cdot 1 \\
0 \cdot 4 \\
0 \cdot 8 \\
0.3 \\
0.5 \\
1 \cdot 3 \\
2 \cdot 1 \\
1 \cdot 1 \\
1 \cdot 6+\end{array}$ & $\begin{array}{l}0.2 \\
0.3 \\
0.3 \\
0.4 \\
0.3 \\
1.1 \\
0.8 \\
2.3 \dagger \\
1.4 \dagger \\
1.3 \\
0.4 \\
0.3\end{array}$ & $\begin{array}{l}0.3 \\
0.3 \\
0.3 \\
0.4 \\
0.5 \\
0.6 \\
0.6 \\
1.3 t \\
0.8 t \\
1.0 \\
0.6 \\
0.2\end{array}$ & $\begin{array}{l}0.2 \\
0.3 \\
0.3 \\
1.3 \\
0.3 \\
0.3 \\
0.8 \\
1.1 \dagger \\
0.8 \\
0.6 \\
0.5 \\
0.3\end{array}$ & $\begin{array}{l}0.2 \\
0.3 \\
0.5 \\
0.8 \\
0.2 \\
0.2 \\
0.7 \\
0.5 \dagger \\
0.4 \\
0.5 \\
0.3 \\
0.3\end{array}$ \\
\hline
\end{tabular}

* The larger of each pair is printed in heavy type.

+ Difference between sexes greater than five-tenths of a millivolt.

therefore considered justified for practical purposes. The coefficients of variation (S.D. $\times 100 / \overline{\mathbf{x}} .$. ) were greater for men on 16 of 35 occasions on which comparison was possible and greater for women on 19 , hardly different from a $1: 1$ ratio. The implication of this is discussed later.

In the case of the $R, S$, and $T$ waves, there was a positive correlation between age and mean variance on 16 occasions and a negative one on $20^{\star}$. This is hardly different from an expected 1:1 ratio, i.e. there was no detectable tendency for mean variance to be related to age. Pooling the data of all subjects irrespective of age was therefore considered justified.

A significant relation between mean variance and mean wave amplitude was found both when the sexes were considered separately and when the whole population was studied. A positive correlation was observed on 33 of 36 occasions, and a negative on only 3 . This is a highly significant difference from the $1: 1$ ratio of positive to negative correlations to be expected on a chance basis $(\mathrm{p}<0.001)$.

Consideration of Individual Waves. The standard deviations and maximal permissible day-to-day differences in the amplitudes of the $P$ waves and the constantly occurring $Q$ waves are listed in Table III. In 27 subjects, a $Q$ wave appeared for the first time after the first recording or, having been present initially, disappeared. The mean potential of such inconsistently occurring $Q$ waves was $0.5 \pm 0.4$ tenths of a millivolt and never exceeded $0.03 \mathrm{sec}$.

$\star$ The coefficient of correlation was computed 36 times, i.e. in the $R, S$, and $T$ waves in each of the 12 leads.
TABLE III

STANDARD DEVIATIONS AND MAXIMAL PERMISSIBLE DAY-TO-DAY DIFFERENCES IN $P$ AND $Q$ WAVES IN TENTHS OF A MILLIVOLT: DATA FOR MEN AND WOMEN POOLED

\begin{tabular}{|c|c|c|c|c|}
\hline \multirow[b]{2}{*}{ Lead } & \multicolumn{2}{|c|}{$P$ wave } & \multicolumn{2}{|c|}{$Q$ wave } \\
\hline & $\begin{array}{l}\text { Standard } \\
\text { deviation }\end{array}$ & Max. diff. & $\begin{array}{l}\text { Standard } \\
\text { deviation }\end{array}$ & Max. diff. \\
\hline $\begin{array}{l}\text { I } \\
\text { II } \\
\text { III } \\
\text { aVR } \\
\text { aVL } \\
\text { aVF } \\
\text { V1 } \\
\text { V2 } \\
\text { V3 } \\
\text { V4 } \\
\text { V5 } \\
\text { V6 }\end{array}$ & $\begin{array}{l}0.1 \\
0.2 \\
0.3 \\
0.3 \\
0.2 \\
0.2 \\
0.1 \\
0.1 \\
0.1 \\
0.1 \\
0.1 \\
0.1\end{array}$ & $\begin{array}{l}0 \cdot 2 \\
0 \cdot 3 \\
0 \cdot 4 \\
0.5 \\
0 \cdot 3 \\
0 \cdot 4 \\
0 \cdot 2 \\
0 \cdot 2 \\
0 \cdot 2 \\
0 \cdot 2 \\
0.2 \\
0.2\end{array}$ & $\begin{array}{l}0 \cdot 1 \\
0 \cdot 1 \\
0 \cdot 2 \\
0 \cdot 3 \star \\
0 \cdot 1 \\
0 \cdot 1 \\
= \\
= \\
0 \cdot 2 \\
0 \cdot 2 \\
0 \cdot 1\end{array}$ & $\begin{array}{l}0.2 \\
0.2 \\
0.3 \\
0 \cdot 4^{\star} \\
0 \cdot 2 \\
0 \cdot 2 \\
= \\
= \\
\overline{0} \cdot 3 \\
0.3 \\
0.2\end{array}$ \\
\hline
\end{tabular}

* Refers to QS pattern.

in duration or two-tenths of a millivolt in potential. Only one chest lead was ever thus affected, invariably the one adjacent to leads with a constant $Q$ wave.

In 46 subjects an $R^{\prime}$ or $S^{\prime}$ was recorded in one or more leads. In 64 leads thus involved an $R^{\prime}$ appeared on all four days. In 11 leads it was inconstant but in these cases very small, never exceeding 1.2 tenths of a millivolt. $R^{\prime}$ in lead V1 was invariably constant, an "incomplete right bundlebranch block pattern" never appearing in later recordings when absent initially, or vice versa. An $S^{\prime}$ was recorded consistently in 9 leads and inconstantly in 6 , but when inconstant it was always very small, in no case exceeding $2 \cdot 2$ tenths of a millivolt. The standard deviations and maximal permissible day-to-day differences in $R$ and $S$ wave amplitudes are listed in Table IV.

TABLE IV

STANDARD DEVIATIONS AND MAXIMAL PERMISSIBLE DAY-TO-DAY DIFFERENCES IN $R$ AND $S$ WAVES IN TENTHS OF A MILLIVOLT: DATA FOR MEN AND WOMEN POOLED

\begin{tabular}{l|c|c|c|c}
\hline \multirow{2}{*}{ Lead } & \multicolumn{2}{|c|}{ R wave } & \multicolumn{2}{c}{ S wave } \\
\cline { 2 - 5 } $\begin{array}{c}\text { Standard } \\
\text { deviation }\end{array}$ & Max. diff. & $\begin{array}{c}\text { Standard } \\
\text { deviation }\end{array}$ & Max. diff. \\
\hline I & 0.5 & 0.9 & 0.2 & 0.4 \\
II & 0.4 & 0.7 & 0.3 & 0.5 \\
III & 0.5 & 0.8 & 0.3 & 0.6 \\
aVR & 0.1 & 0.2 & 0.4 & 0.6 \\
aVL & 0.4 & 0.7 & 0.4 & 0.7 \\
aVF & 0.6 & 1.0 & 0.9 & 1.5 \\
V1 & 0.3 & 0.5 & 0.8 & 1.3 \\
V2 & 0.6 & 1.0 & 2.0 & 3.2 \\
V3 & 1.5 & 2.4 & 1.2 & 2.0 \\
V4 & 2.2 & 3.6 & 1.2 & 2.0 \\
V5 & 1.3 & 2.1 & 0.5 & 0.8 \\
V6 & 1.2 & 1.9 & 0.2 & 0.4 \\
\hline
\end{tabular}


The standard deviations and maximal permissible day-to-day differences in S-T segment depression or elevation are listed in Table $V$. The $T$ wave was inverted in leads III, aVF, and V1 in a minority of patients. In 9 subjects there was a change of direction of the T wave in lead III. Having been upright initially, it became inverted or, having been inverted initially, it became upright. Changes in direction of the $T$ wave in lead III were not associated with detectable changes of a reciprocal nature in lead I or with any consistent alteration in direction of the frontal plane QRS axis. The waves

\section{TABLE V}

STANDARD DEVIATIONS AND MAXIMAL PERMISSIBLE DAY-TO-DAY DIFFERENCES IN S-T SEGMENTS AND T WAVES IN TENTHS OF A MILLIVOLT: DATA FOR MEN AND WOMEN POOLED

\begin{tabular}{l|c|c|c|c}
\hline \multirow{2}{*}{ Lead } & \multicolumn{2}{|c|}{ S-T segments } & \multicolumn{2}{|c}{ T waves } \\
\cline { 2 - 2 } & $\begin{array}{c}\text { Standard } \\
\text { deviation }\end{array}$ & Max. diff. & $\begin{array}{c}\text { Standard } \\
\text { deviation }\end{array}$ & Max. diff. \\
\cline { 5 - 5 } I & 0.3 & 0.4 & 0.2 & 0.4 \\
II & 0.1 & 0.2 & 0.3 & 0.5 \\
III & 0.1 & 0.2 & 0.4 & 0.6 \\
aVR & 0.1 & 0.2 & 1.1 & 1.8 \\
aVL & 0.1 & 0.2 & 0.2 & 0.4 \\
aVF & 0.1 & 0.2 & 0.2 & 0.4 \\
V1 & 0.2 & 0.3 & 0.8 & 1.3 \\
V2 & 0.1 & 0.2 & 0.9 & 1.5 \\
V3 & 0.2 & 0.3 & 0.6 & 1.1 \\
V4 & 0.2 & 0.3 & 0.5 & 0.9 \\
V5 & 0.1 & 0.2 & 0.4 & 0.7 \\
V6 & 0.1 & 0.2 & 0.3 & 0.5 \\
\hline
\end{tabular}

TABLE VI

COEFFICIENTS OF VARIATION OF R AND S WAVES AND MAXIMAL PERMISSIBLE DAY-TO-DAY DIFFERENCESEXPRESSED AS PERCENTAGES OF WAVE AMPLITUDES (MAX. PER CENT DIFF.)

\begin{tabular}{|c|c|c|c|c|}
\hline \multirow[b]{2}{*}{ Lead } & \multicolumn{2}{|c|}{$R$ wave } & \multicolumn{2}{|c|}{$S$ wave } \\
\hline & $\begin{array}{c}\text { Coefficient } \\
\text { of variation }\end{array}$ & $\begin{array}{l}\text { Max. per } \\
\text { cent diff. }\end{array}$ & $\begin{array}{c}\text { Coefficient } \\
\text { of variation }\end{array}$ & $\begin{array}{l}\text { Max. per } \\
\text { cent diff. }\end{array}$ \\
\hline $\begin{array}{l}\text { I } \\
\text { II } \\
\text { III } \\
\text { aVR } \\
\text { aVL } \\
\text { aVF } \\
\text { V1 } \\
\text { V2 } \\
\text { V3 } \\
\text { V4 } \\
\text { V5 } \\
\text { V6 }\end{array}$ & $\begin{array}{r}8.4 \\
4.3 \\
10.9 \\
\overrightarrow{12.1} \\
9.5 \\
\overline{9.4} \\
15.2 \\
13.7 \\
7.7 \\
10.0\end{array}$ & $\begin{array}{r}14 \\
7 \\
18 \\
20 \\
16 \\
15 \\
25 \\
23 \\
13 \\
16\end{array}$ & $\begin{array}{c}\bar{Z} \\
16 \cdot 4 \\
5 \cdot 5 \\
\overline{7} \\
8 \cdot 3 \\
13 \cdot 2 \\
11 \cdot 2 \\
17 \cdot 6 \\
=\end{array}$ & $\begin{array}{l}\overline{-} \\
27 \\
\frac{9}{-} \\
\overline{14} \\
22 \\
18 \\
29 \\
=\end{array}$ \\
\hline
\end{tabular}

concerned were very small, the greatest upright and the most deeply inverted TIII to change direction measuring 1.2 and $1 \cdot 1$ tenths of a millivolt, respectively. TaVF changed direction once, from $+0 \cdot 1$ to -0.4 tenths of a millivolt. TV1 changed direction in 15 subjects, the greatest positive and negative deflections observed in this group being +1.5 and $-1 \cdot 2$ tenths of a millivolt, respectively. $T$ waves greater than 1.5 tenths of a millivolt were invariably constant in direction. The standard deviations and maximal permissible day-to-day differences in amplitude of the $T$ wave, whether inverted or upright, are listed in Table $\mathrm{V}$ and allow for possible change of direction.

\section{Discussion}

The present study was designed primarily to establish standards whereby the significance of minor day-to-day changes in the electrocardiogram could be assessed in patients in hospital with chest pains of indeterminate nature. In such patients, recording of serial electrocardiograms under carefully standardized conditions is feasible and, in the absence of obvious stigmata of coronary insufficiency, two or three days' delay in making a diagnosis is acceptable. An example is shown in the Figure. The patient was a 63-year-old man with chest pain suggestive of myocardial ischæmia. The electrocardiograms, separated by four days, can each be considered normal. However, there are appreciable changes in $T$ wave amplitudes which are greater in the later tracing. Whether such changes are abnormal or not has hitherto been unknown. The present findings suggest that they would be abnormal in electrocardiograms recorded under standardized conditions.

As long ago as 1912, Lewis and Gilder reported the results of comparing serial tracings in individual subjects, but the conditions were not standardized and in many cases the tracings were taken several years apart and with different instruments. Even with the lapse of half a century the short-term repeatability of the electrocardiogram in any one person has received little attention. The closest approximation to the present study was made by Simonson et al. (1949). Although they confined their investigations to healthy young male students aged 20 to 30 years, their results were similar to ours.

In the present study, the technique of recording was designed to minimize effects of factors external to the heart, such as patient position, siting of chest lead electrodes, reflex changes, meals, tobacco, and drugs. It was not possible to eliminate completely the effects of emotional factors, but every endeavour to minimize them was made. Subjects with known psychological disturbances were excluded. Patients were reassured about their cardiovascular status. On the whole, they seemed relaxed and the insignificance of any emotional disturbances was further suggested by the near constancy of the heart rate from day to day. Any effects of anxiety might have been expected to be greatest on the first day, resulting in differences between the first and second tracings greater than the differences between the third 

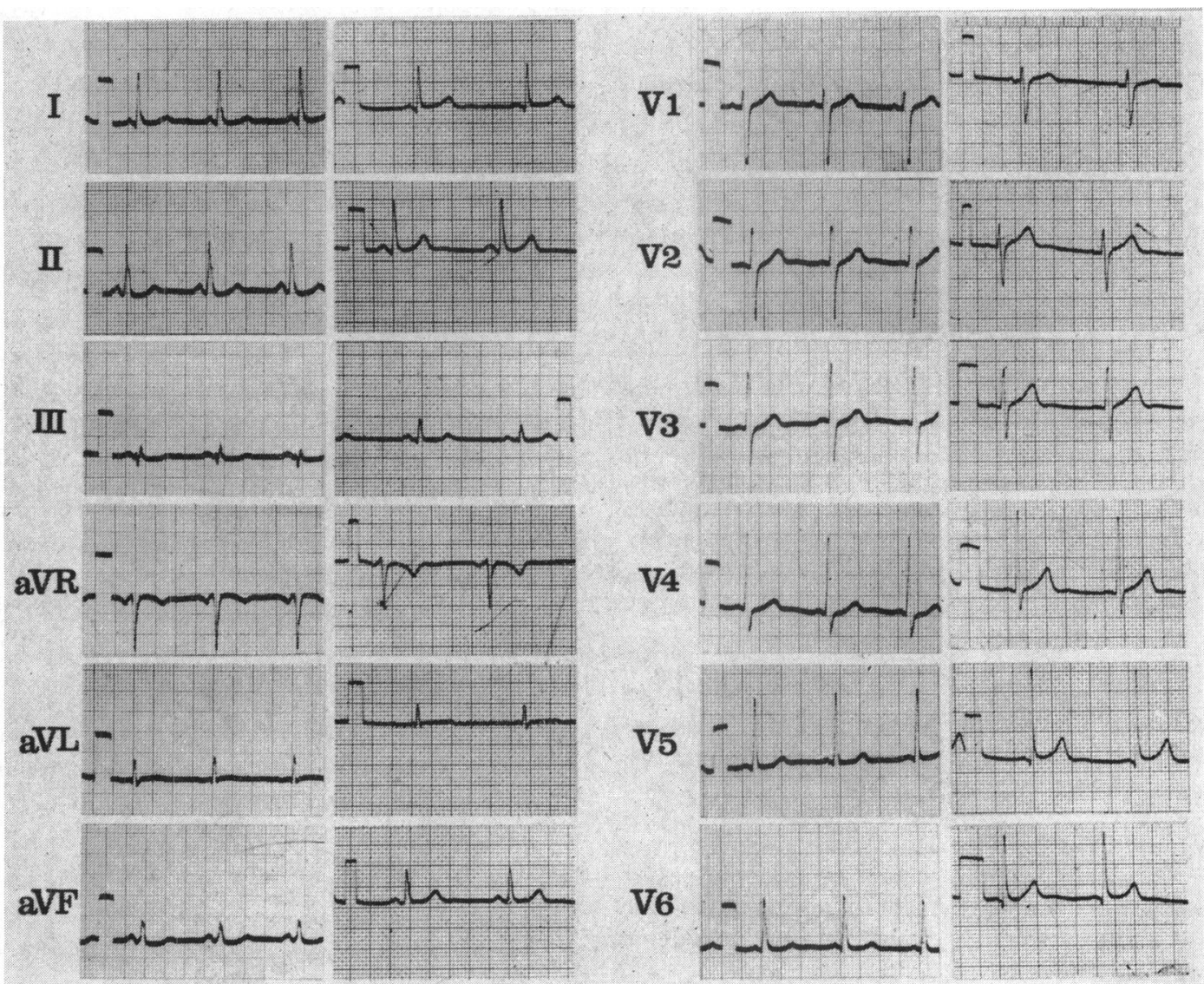

FIG.-Electrocardiograms recorded with four-day interval in patient with suspect acute coronary insufficiency.

The earlier tracings are on the left, the later on the right.

and fourth. In fact, the variations between the first two days and between the last two days did not differ significantly.

The present findings show that the rhythm may change normally from complete regularity to sinus arrhythmia, and occasional atrial or ventricular ectopic beats appear de novo. Changes in frontal plane QRS axis of more than $10^{\circ}$ can be considered significant. Our observations suggest that serial studies may be of value in assessing the significance of lengthening of the P-R or QRS intervals that may occur within the over-all limits of normal, providing in the latter case that there is a clear demarcation between the end of the upstroke of the $S$ wave and the beginning of the S-T interval.

Splintering or notching of an $R$ or an $S$ wave may appear normally in the course of serial recordings or, having been present initially, may subsequently disappear. The general configuration of the electrocardiogram is, however, constant and any marked change in contour is to be considered abnormal.
An example would be an S-T segment that initially sloped upward and merged with the $T$ wave, becoming horizontal and clearly demarcated from the $T$ wave.

The present results show that day-to-day $P$ wave amplitude variations are normally minimal (Table III). A Q wave can appear de novo in a limb or in a single chest lead, but more extensive spread of $Q$ waves in serial chest lead recordings does not appear to occur normally. Furthermore, it should be considered highly unusual for a newly appearing $Q$ wave to exceed $0.02 \mathrm{sec}$. in duration or 1.2 tenths of a millivolt in potential. Table III lists the maximal permissible differences in size of constantly appearing $Q$ waves. Greater changes should be considered abnormal even if the $Q$ waves in individual electrocardiograms are within normal limits. In practice, increase is more important than decrease in size, and the main value of Table III is in providing criteria by which the significance of day-today increases in $Q$ wave size can be assessed. 
The present observations suggest that appearance or disappearance of prime waves greater than twotenths of a millivolt is to be considered abnormal, as is day-to-day appearance or disappearance of an "incomplete right bundle-branch block pattern". This is of considerable practical importance as this pattern may occur normally in leads V1 and V2 and yet on occasion be a manifestation of acute right ventricular overload.

The mean $R, S$, and $T$ wave variances of the chest leads tended to be larger in men than in women. There was no correlation between mean variance and age, and the average ages of the sexes were almost identical (men $45 \cdot 4 \pm 12 \cdot 1$ years, women $45 \cdot 3 \pm 11 \cdot 4$ years). Sex differences in variability do not, therefore, appear to be a function of age. The chest lead electrocardiographic complexes tended to be larger in the men, as has been noted by other investigators (Simonson et al., 1960), and the present study shows a significant positive correlation between mean wave amplitude and mean variance. This raises the possibility of the observed sex differences in mean variance being a function of sex differences in wave amplitude, and that this explanation is correct is suggested by the results of comparing the coefficients of variation of the men and the women. When day-to-day variability is thus expressed as a proportion of wave amplitude, the differences between the sexes disappear. The sex differences in mean variance are very small. The greatest inaccuracy in standard deviation produced in any wave as a result of using the pooled data for the sexes instead of the separately calculated standard deviations for the men and for the women is only 0.7 tenths of a millivolt. For practical purposes, therefore, pooling the data obtained in each sex may be considered justified.

As mean variance correlates positively with mean wave amplitude, the maximal permissible daily differences tabulated are overestimates when waves are less than the mean and underestimates when waves are greater. Any inaccuracies thus produced are unlikely to be appreciable in the $P$ and $Q$ waves and the S-T segments, as their amplitude scatter about their means is extremely small. No analysis of their amplitude variance relationships was therefore attempted. With $R, S$, and $T$ waves of near average potential, corrections for wave amplitude are unlikely to increase appreciably the accuracy of estimates of maximal permissible day-to-day differences. Even when individual $\mathrm{T}$ waves approach the limits of normal, the over- or underestimates resulting from use of the maximal permissible differences listed in Table $V$ are very small. They amount to about 0.5 tenth of a millivolt in the limb leads and 1.0 tenth of a millivolt in leads V3-5.
Under- or overestimates resulting from using the maximal permissible differences listed in Table IV only become appreciable in leads characterized by large $R$ or $S$ waves and when individual $R$ and $S$ waves approach the limits of normal. In such cases increased accuracy may be obtained by use of Table VI, where the maximum permissible daily differences have been expressed as a percentage obtained by multiplying the coefficient of variation by 1.645 .

The findings suggest that the value of the electrocardiogram in detecting early or minor departures from normal may be enhanced greatly by making serial observations under standardized conditions and comparing the changes observed with the listed maximal permissible day-to-day differences. Abnormalities can thus be detected by comparing tracings, even though individual recordings are within normal limits.

\section{SUMMARY}

Electrocardiograms were recorded under carefully standardized conditions on each of four consecutive days in 36 men and 22 women aged 30 to 70 years. All were clinically free of heart disease and the electrocardiograms were individually normal.

The tracings were examined for qualitative changes and measurements made of the daily variations in the P-R and QRS intervals, the levels of the $S-T$ segments, and the amplitudes of the $P, Q, R, S$, and $T$ waves. The limits of normal for the day-to-day variability of the electrocardiogram were determined statistically for each of these features and tabulated. It is suggested that if these limits are exceeded in consecutive daily electrocardiograms recorded under standardized conditions, the series should be considered abnormal even though the tracings are individually normal.

We are grateful to Dr. F. A. L. Mathewson and Professor B. A. Hodson for use of the facilities of the Department of Electrocardiography, Winnipeg General Hospital, and the Computer Department of the University of Manitoba. We are also indebted to Professor G. I. Paul for statistical advice and to Dr. J. E. Klovan for help with the computer programming.

\section{REFERENCES}

Goldberger, E. (1949). Unipolar Lead Electrocardiografhy, 2nd ed., pp. 116-125. Lea and Febiger, Philadelphia.

Hiss, R. G., Lamb, L. E., and Allen, M. F. (1960). Electrocardiogr aphic findings in 67,375 asymptomatic subjects X. Normal values. Amer. F. Cardiol., 6, 200.

Kossmann, C. E., and Johnston, F. D. (1935). The precordial electrocardiogram. I. The potential variations of the precordium and of the extremities in normal subjects. Amer. Heart f., 10, 925.

Lewis, T., and Gilder, M. D. D. (1912). The human electro- 
cardiogram; a preliminary investigation of young male adults, to form a basis for pathological study. Phil. Trans. $B, 202,351$.

Myers, G. B., Klein, H. A., Stofer, B. E., and Hiratzka, T. (1947). Normal variations in multiple precordial leads. Amer. Heart f., 34, 785.

New York Heart Association (1964). Diseases of the Heart and Blood Vessels. Nomenclature and Criteria for Diagnosis, 6th ed., pp. 418-438. Little Brown, Boston.
Simonson, E., Blackburn, H., Jr., Puchner, T. C., Eisenberg, P., Ribeiro, F., and Meja, M. (1960). Sex differences in the electrocardiogram. Circulation, 22, 598.

- - Brozek, J., and Keys, A. (1949). Variability of the electrocardiogram in normal young men. Amer. Heart J., 38, 407.

Sokolow, M., and Friedlander, R. D. (1949). The normal unipolar precordial and limb lead electrocardiogram. Amer. Heart f., 38, 665. 